\title{
Influence of elastin-derived peptides, glucose, LDL and oxLDL on nitric oxide synthase expression in human umbilical artery endothelial cells
}

\author{
Wojciech Garczorz ${ }^{\circledR}$, Tomasz Francuz¹, Jan Gmiński, Wirginia Likus², \\ Krzysztof Siemianowicz ${ }^{1}$, Teresa Jurczak ${ }^{1}$ and Barbara Strzałka-Mrozik ${ }^{3}$
}

1Department of Biochemistry, ${ }^{2}$ Department of Human Anatomy, Medical University of Silesia, Katowice; ${ }^{3}$ Department of Molecular Biology, Medical University of Silesia, Sosnowiec, Poland

Endothelial dysfunction plays an important role in the development of atherosclerosis. Elastin-derived peptides (EDP), hyperglycemia, hypercholesterolemia and oxidized LDL have a proven proatherosclerotic potential. Nitric oxide generated by endothelial nitric oxide synthase (eNOS; EC 1.14.13.39) is an important vasorelaxant. Here we studied the influence of those proatherosclerotic factors on eNOS gene and protein expression in artery-derived endothelial cells. Human umbilical artery endothelial cells (HUAEC) were incubated with or without: glucose $(270 \mathrm{mg} / \mathrm{dl}), \mathrm{LDL}(200 \mathrm{mg} / \mathrm{dl})$, oxidized LDL (oxLDL $25 \mathrm{mg} / \mathrm{dl}$ ) or K-elastin $(0.5$ and $2.5 \mu \mathrm{g} / \mathrm{ml})$. Gene expression was assessed by real time RT-PCR, whilst the eNOS protein by ELISA. In cells incubated with $2.5 \mu \mathrm{g} /$ $\mathrm{ml}$ of K-elastin, a $31 \%$ increase of eNOS mRNA expression was observed, but the protein level remained unchanged. OxLDL, LDL and glucose decreased the eNOS protein level by $74 \%, 37 \%$ and $29 \%$, respectively. OxLDL decreased eNOS mRNA by $42 \%$. LDL non-significantly decreased eNOS mRNA expression. An elevated glucose level did not affect the eNOS mRNA expression. Hyperglycemia and an elevated level of LDL, particularly oxLDL, decreased the level of eNOS protein in endothelial cells. As K-elastin did not decrease the expression of eNOS gene in HUAEC, the proatherogenic properties of elastin-derived peptides are unlikely to be due to their influence on eNOS

Keywords: endothelium, elastin-derived peptides, EDP, atherosclerosis, hyperglycemia, LDL, oxidized LDL, nitric oxide synthase, eNOS

Received: 05 March, 2011; revised: 27 March, 2011; accepted: 09 July, 2011; available on-line: 11 July, 2011

\section{INTRODUCTION}

Human endothelium covers the inner surface of blood vessels and constitutes a huge endocrine gland. The theory of unified response to injury, formulated by Ross (1999), postulates a stereotypic vascular wall reaction in response to various types of endothelial injury. When the endothelium remains undamaged, the vasodilatative function prevails. Endothelial damage shifts the balance towards vasoconstriction and atherothrombosis. Nitric oxide generated by nitric oxide synthase (NOS) is a potent vasorelaxant. Although endothelial nitric oxide synthase (eNOS) is a constitutively expressed enzyme, its activity and expression level is influenced by certain factors.
A decrease in nitric oxide bioavailability may be caused by many factors: decreased expression of eNOS, a lack of eNOS substrates or cofactors, accelerated NO degradation or inactivation of eNOS due to dephosphorylation of Ser1177 (Cai \& Harrison, 2000). The most important cause of endothelial dysfunction is accelerated NO degradation by reactive oxygen species (ROS), especially superoxide anion $\mathrm{O}_{2}^{-}$. The reaction between $\mathrm{NO}$ and $\mathrm{O}_{2}^{-\cdot}$ is extremely rapid. It occurs three times faster than the dismutation of $\mathrm{O}_{2}^{-}$by superoxide dismutase (SOD). The product of this reaction - peroxynitrite - is a powerful trigger of p38 mitogen-activated protein kinase (MAPK) phosphorylation and activation in cells of cardiac, vascular and neural origin (Liaudet et al., 2009). In view of the effect of MAPK in triggering vascular smooth muscle cells' hypertrophy and proliferation, blocking the MAPK cascade probably could reverse vascular dysfunction in patients with heart failure (Ogut \& Brozovich, 2008). Even a moderate increase in $\mathrm{O}_{2}^{-}$ production may cause a serious depletion of NO. This may lead to oxidative stress and endothelial dysfunction. Inactivation of $\mathrm{NO}$ by oxidative stress is involved in many conditions, such as atherosclerosis, diabetes, hypertension and hypercholesterolemia. The most important enzymatic systems involved in ROS production are: NADH/NADPH oxidase, xanthine oxidase and uncoupled eNOS. Nitric oxide is a potent activator of soluble guanylyl cyclase (sGC) which produces cyclic guanosine monophosphate (cGMP). cGMP activates protein kinase $G$ (PKG) which leads to calcium-dependent smooth muscle relaxation.

Elastin-derived peptides (EDP) are produced in the process of elastin fiber degradation. EDP occur in human blood in a wide range of concentrations, from $10^{-6}$ to $10^{-2} \mathrm{mg} / \mathrm{ml}$ (Fulop et al., 1990). Oligopeptide sequences VGVAPG are present in both insoluble elastin and EDP. As these sequences activate the elastin receptor, EDP can exert most of elastin's biological effects.

Elastin shows slow turnover, which is accelerated in atherosclerosis, diabetes, lung emphysema, arthritis or neoplasms (Hornebeck \& Robert, 1977). Elastin-derived peptides stimulate synthesis and the release of metaloproteases and reactive oxygen species. In experimen-

\footnotetext{
e-mail: wojtekx@mp.pl
}

Abbreviations: EDP, elastin-derived peptides; eNOS, endothelial nitric oxide synthase; GAPDH, glyceraldehyde 3-phosphate dehydrogenase; HUAEC, human umbilical artery endothelial cells; LDL, low density lipoprotein; MAPK, mitogen-activated protein kinase; NOS nitric oxide synthase; oxLDL, oxidized low density lipoprotein; PBS, phosphate-buffered saline 
Table 1. Sequences of primers and probes used in quantitative RT-PCR of eNOS and GAPDH genes

\begin{tabular}{ll}
\hline GAPDH-Forward & 5'-GAA GGT GAA GGT CGG AGT-3' \\
GAPDH-Reverse & 5'-GAA GAT GGT GAT GGG ATT TC-3' \\
GAPDH-Probe & 5'-(FAM)-CAA GCT TCC CGT TCT CAG CC-(TAMRA)-3' \\
eNOS- Forward & 5'-GTG GCT GTC TGC ATG GAC CT-3' \\
eNOS-Reverse & 5'-CCA CGA TGG TGA CTT TGG CT-3' \\
eNOS-Probe & 5'-(FAM)-AGT GGA AAT CAA CGT GGC CGT GCT-(TAMRA)-3' \\
\hline
\end{tabular}

The oxidized LDL was dialyzed for 3 days against three changes of the PBS buffer with EDTA, in the dark, at $4^{\circ} \mathrm{C}$. After the final sterile filtration (Millex, Millipore), LDL and oxLDL were stored refrigerated under argon for no longer than 2 weeks. The concentration of LDL was determined by total cholesterol assay. Additionally, the total LDL-protein concentration was determined by the bicinchoninic acid method (Sigma). LDL and oxLDL purity was checked spectrophotometrically and by electrophoresis (Paragon Lipo, Beckman Coulter).

tal studies, rabbits receiving EDP injections developed atherosclerosis (Gmiński \& Dróżdż, 1991). Moreover, as children from families with high risk of atherosclerosis present a significantly increased serum level of EDP, it seems that disturbances of elastin metabolism may play a primary role among the risk factors for atherosclerosis (Gmiński et al., 1991). Accordingly, we endeavored to evaluate the mechanism of atherosclerosis induction by EDP and their influence on eNOS expression.

Low density lipoproteins, oxLDL and hyperglycemia are considered potent factors that can negatively affect the arterial wall. Diabetes mellitus causes many vascular complications classified as macro- or microangiopathies. Diabetes mellitus increases up to 4-fold the risk of atherosclerotic complications as compared to individuals without carbohydrate metabolism disturbances. Attempts have been made to evaluate the influence of the abovementioned factors on the eNOS gene expression, however, the results are divergent (Braam \& Verhaar, 2007).

\section{MATERIALS AND METHODS}

Endothelial cell culture. Human umbilical artery endothelial cells (HUAEC) were used in this experiment. Umbilical cord was chilled in Hank's solution immediately after delivery. The cells were isolated by mild digestion of the umbilical artery with $0.1 \%$ collagenase dissolved in M199 culture medium (Gibco). HUAEC were incubated in EBM-2 culture medium supplemented with $10 \%$ foetal bovine serum and EGM-2 MV SingleQuots (Lonza) at $37^{\circ} \mathrm{C}$ in $5 \% \mathrm{CO}_{2}$ humidified incubator on fibronectin-coated (Sarstedt) tissue culture flasks. The cells were detached from the flasks following 1\% trypsin (Gibco) treatment. After each passage, the cells were incubated for $48 \mathrm{~h}$ to ensure monolayer. HUAEC were identified using monoclonal antibody against von Willebrand factor and by their typical morphology. Cell viability and morphology were assessed for each experimental group. The procedure of cell isolation and the experimental protocol were approved by the local Bioethics Committee.

Isolation and oxidation of LDL. Fresh plasma from healthy donors was obtained from the local Blood Bank in Katowice. LDL was isolated from fresh human plasma according to Garland's protocol (Garland, 2002). LDL solution was concentrated in Millipore UltrafreeCL centrifugal ultrafilters. The collected stock solution was dialyzed in dialysis tubes MWCO 50000 (Spectrum Labs) against a PBS buffer with $0.2 \mathrm{mM}$ EDTA, in the dark, at $4^{\circ} \mathrm{C}(5 \mathrm{ml}$ against 11 of PBS, 3 days, two buffer changes). The part of LDL that was to undergo oxidation was dialyzed against PBS without EDTA. The oxidation of LDL was induced by incubation in dialysis tubes with PBS buffer supplemented with $10 \mu \mathrm{M} \mathrm{Cu}{ }^{2+}$, in the dark, at $21^{\circ} \mathrm{C}$ for $24 \mathrm{~h}$ (Galle \& Wanner, 1998).
eNOS protein assay. Immediately after incubation, the cells were detached from flasks by trypsinization, washed twice with PBS buffer and centrifuged $(5 \mathrm{~min}$, $2000 \mathrm{rpm})$. They were then lysed with $0.5 \mathrm{ml}$ of cooled Cell Lysis Solution (R\&D). The eNOS protein assay was performed with the use of the human eNOS Immunoassay kit (R\&D), in compliance with manufacturer's instructions. Absorbance was measured at 450 and 545 nm with a Stat Fax 2100 Microplate Reader. The total protein concentration was determined with the bicinchoninic acid method.

RNA isolation. Cytoplasmic RNA was isolated using the RNeasy Mini Kit (Qiagen) in compliance with manufacturer's protocol. Approximately $10^{5}$ cells were lysed with $175 \mu \mathrm{l}$ of sterile RLN buffer containing: 50 $\mathrm{mM}$ Tris/ $\mathrm{HCl}, 140 \mathrm{mM} \mathrm{NaCl}, 1.5 \mathrm{mM} \mathrm{MgCl}_{2}$, and $0.5 \%$ IGEPAL CA630, pH 8.0. Immediately before isolation, $2 \mathrm{mM}$ dithiothreitol was added to the RLN buffer. The lysis was performed for 5 minutes in an ice bath. The lysate was centrifuged ( $2 \mathrm{~min}, 2000 \mathrm{rpm}$ ) and the supernatant without nuclei was transferred to another testtube. The subsequent steps of the procedure were carried out in compliance with the manufacturer's manual. The purity and concentration of the isolated RNA were measured spectrophotometrically using GeneQuant II.

Quantitative RT-PCR. The quantitative measurement of gene expression was performed with an Abi Prism 7000 (Applied Biosystems). The primers and probe for eNOS were based on sequences described previously (Dötsch et al., 2001) and corrected by the author (unpublished). The primers and probe for the housekeeping gene (GAPDH) were synthesized according to the Applied Biosystems recommendations. To avoid potential amplification from DNA, both amplicons spanned introns (Table 1).

For amplification, the commercially available TaqMan EZ RT-PCR Kit (Applied Biosystems) and dNTP (Fermentas) were used. The thermocycler parameters were: $58^{\circ} \mathrm{C}$ for $32 \mathrm{~min}$ (reverse transcription), $95^{\circ} \mathrm{C}$ for $2 \mathrm{~min}$ (initial denaturation), followed by 35 cycles at $94^{\circ} \mathrm{C}$ for $1 \mathrm{~min}$ (denaturation), $60^{\circ} \mathrm{C}$ for $1 \mathrm{~min}$ (annealing), $68^{\circ} \mathrm{C}$ for $30 \mathrm{~s}$ (extension). The expression of endothelial nitric oxide synthase was determined by means of the comparative $\Delta \Delta C T$ method. Before its application for quantitation, a validation experiment was performed. A serial dilution of RNA was amplified under the same conditions to demonstrate that the efficiency of target (eNOS) and reference (GAPDH) amplifications were approximately equal.

Experiment design. In all experiments, the fourth passage of cells was used. HUAEC were incubated with the tested substances for $48 \mathrm{~h}$. Before the experiment, cells were incubated for $24 \mathrm{~h}$ in serum-free medium. HUAEC from each flask were halved. The isolation of 

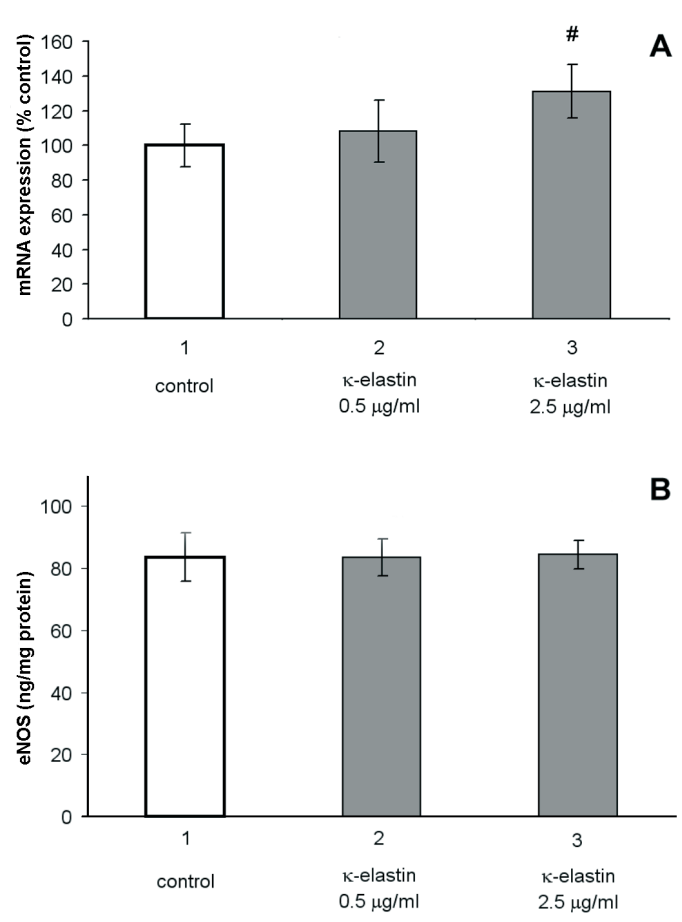

Figure 1. Effects of $\mathrm{k}$-elastin on eNOS mRNA and protein quantity in HUAEC

Cells were incubated with or without (control) k-elastin ( 0.5 or 2.5 $\mu \mathrm{g} / \mathrm{ml}$ ) for 48 hours. eNOS mRNA (A) or protein (B) was quantitated as described in Materials and Methods. The results represent mean \pm S.D. of 4 experiments. ${ }^{*} p \leq 0.01 \mathrm{vs}$. control.

RNA and total protein was performed for each part of the cells as described previously.

Statistical analysis. All values are expressed as mean \pm S.D. To determine the significance of differences between groups, the ANOVA test followed by Tukey's and Scheffe's post hoc tests were used. To compare the study groups exclusively with the control, the Dunnett's test was used.

\section{RESULTS}

$x$-Elastin at a concentration of $0.5 \mu \mathrm{g} / \mathrm{ml} \mathrm{did}$ not affect eNOS mRNA expression or the protein level. In cells incubated with $2.5 \mu \mathrm{g} / \mathrm{ml}$ of $x$-elastin, a $31 \%$ $(p \leq 0.001)$ increase in eNOS mRNA expression was observed, whilst the protein quantity remained unchanged (Fig. 1). OxLDL decreased the eNOS mRNA level by $42 \% \quad(p \leq 0.001)$. Although LDL caused a decrease in eNOS expression, the effect was not statistically significant. An elevated glucose concentration did not affect mRNA expression of eNOS (Fig. 2).

OxLDL, LDL and elevated glucose decreased eNOS protein concentration by $74 \%, 37 \%$ and $29 \%$ (all $p \leq 0.001)$, respectively.

Cells stimulated with high glucose and $x$-elastin showed a $24 \% \quad(p \leq 0.001)$ increase in the amount of eNOS protein, compared to the cells stimulated by glucose only. In the remaining groups tested, the addiction of $x$-elastin to LDL or oxLDL did not affect eNOS protein or mRNA concentrations (Fig. 3).
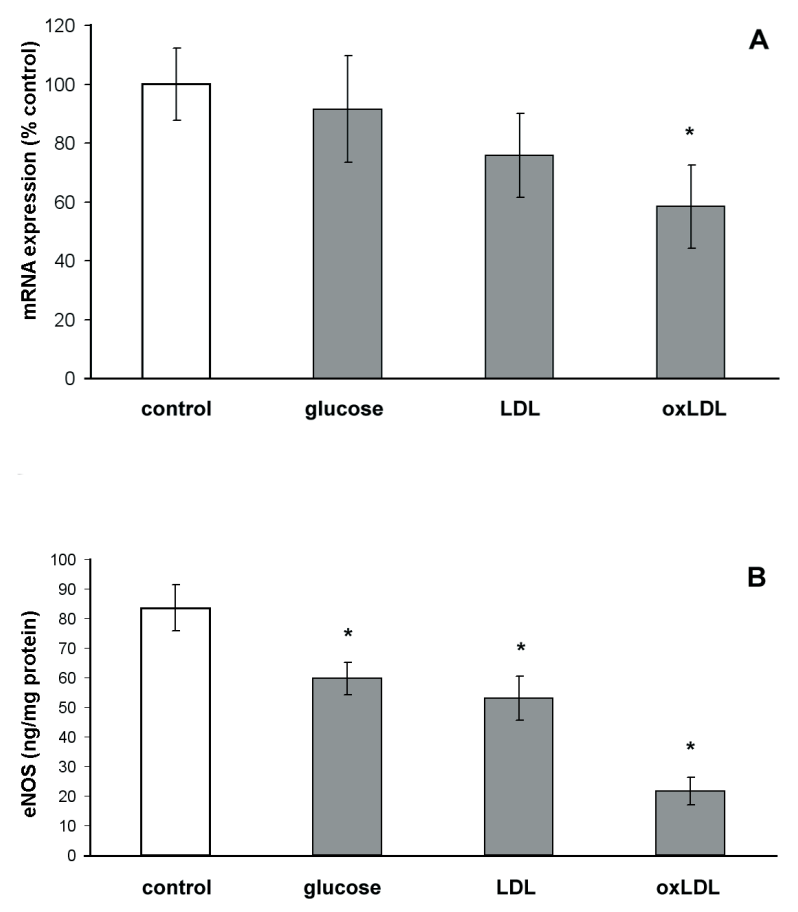

Figure 2. Effects of glucose, LDL, and oxLDL on eNOS mRNA and protein quantity in HUAEC

Cells were incubated with or without (control) glucose $(270 \mathrm{mg} /$ $\mathrm{dl}), \mathrm{LDL}(200 \mathrm{mg} / \mathrm{dl})$ and oxLDL $(25 \mathrm{mg} / \mathrm{dl})$ for 48 hours. eNOS mRNA (A) or protein (B) was quantitated as described in Materials and Methods. The results represent mean \pm S.D. of 4 experiments. ${ }^{*} p \leq 0.001$ vs. control.
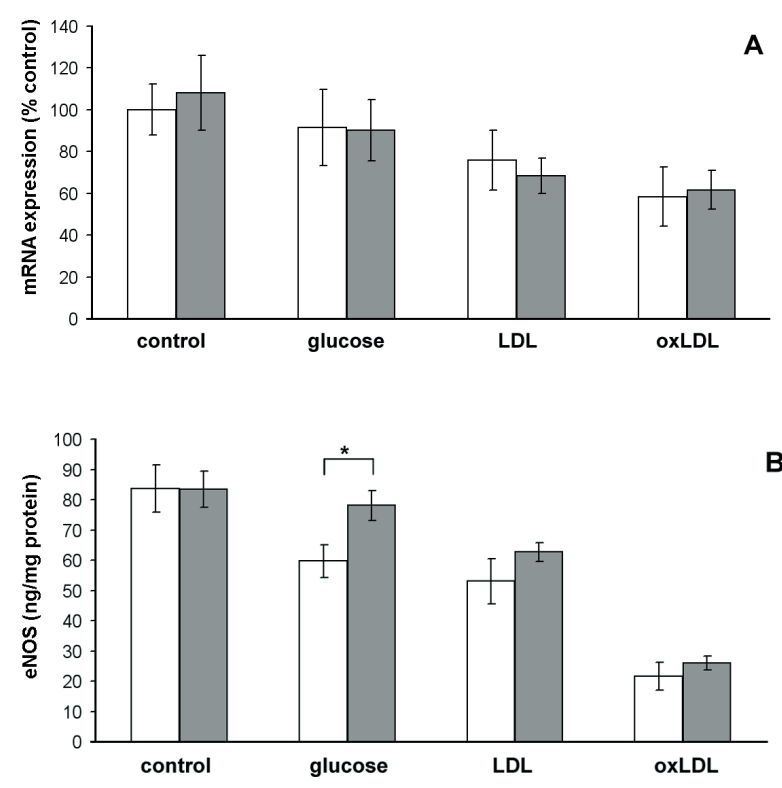

Figure 3. Comparison of the effect of glucose, LDL and oxLDL on eNOS mRNA and protein quantity in the absence (white bars) or presence (gray bars) of K-elastin in HUAEC

Cells were incubated with glucose $(270 \mathrm{mg} / \mathrm{dl}), \mathrm{LDL}(200 \mathrm{mg} / \mathrm{dl})$, oxLDL $(25 \mathrm{mg} / \mathrm{dl})$ and K-elastin $(0.5 \mu \mathrm{g} / \mathrm{ml})$ for 48 hours. eNOS mRNA (A) or protein (B) was quantitated as described in Materials and Methods. The results represent mean \pm S.D. of 4 experiments. ${ }^{*} p \leq 0.001$ presence $v s$. absence of k-elastin. 


\section{DISCUSSION}

Although several studies evaluating the influence of various proatherosclerotic factors on the eNOS gene expression have been performed, their results are divergent. It is hypothesised that the physiology of human umbilical arterial endothelial cells (HUAEC) may differ from human umbilical vein endothelial cells (HUVEC) used in the majority of studies. Because of the similarity between the various types of human arterial endothelial cells, in our study HUAEC were used. The LDL concentration chosen for the presented study can be observed in humans with dyslipidemia and other metabolic disorders. It is a concentration that leads to atherosclerosis in vivo and is considered as "very high" according to the National Cholesterol Education Program Adult Treatment Panel III (Stone et al., 2005). Our experiment proved that LDL cholesterol at $200 \mathrm{mg} / \mathrm{dl}$ significantly decreased the amount of eNOS protein in the studied endothelial cells. The $24 \%$ reduction of eNOS gene expression was not statistically significant. Pritchard et al. (2002) observed an increase in the amount of eNOS protein caused by LDL in bovine arterial endothelial cells (BAEC). Opposite results were reported by Jiménez et al. (2001) who compared endothelial cells from the aortas of rabbits on hypercholestrolemic and standard diet. The reduction of eNOS was observed both on the level of gene expression and the protein amount, but they achieved a very high plasma cholesterol concentration $(900 \mathrm{mg} / \mathrm{dl})$. The reduction of the amount of eNOS in human endothelial cells observed in our study may be caused by decreased eNOS mRNA stability.

There is strong evidence regarding the influence of oxidized LDL on endothelial nitric oxide synthase. Liao et al. (1995) reported that the expression of eNOS mRNA in cultured endothelial cells was decreased by oxLDL at $15-60 \mathrm{mg} / \mathrm{dl}$ in a proportional manner. In the presented study, oxLDL concentration of $25 \mathrm{mg} / \mathrm{dl}$ was chosen and it did not present cytotoxic properties. Moreover, oxLDL had the strongest inhibitory effect on both the eNOS gene expression and protein quantity.

The results of studies evaluating the influence of hyperglycemia on eNOS gene expression are inconsistent, probably due to the diversity of experimental models used. Cosentino et al. (1997) evaluated eNOS gene expression in cultured endothelial cells derived from the human aorta. Five days of incubation with the addition of $400 \mathrm{mg} / \mathrm{dl}$ glucose resulted in a 2-fold increase of both mRNA and eNOS protein. Srinivasan et al. (2004) incubated aortic endothelial cells with the addition of $450 \mathrm{mg} / \mathrm{dl}$ glucose. Initially, an increase in both eNOS $\mathrm{mRNA}$ and protein amount were observed, however, after the first 24 hours the amount of eNOS protein began to decrease, whilst mRNA remained elevated. Our experiment was performed with a lower glucose concentration $(270 \mathrm{mg} / \mathrm{dl})$, which was closer to the blood glucose level observed in patients with uncontrolled diabetes mellitus. After 48 hours of incubation, a 29\% decrease of eNOS protein level was observed $(p \leq 0.001)$, whilst the gene expression remained unchanged.

As $x$-elastin displays all the biological effects of EDP and is widely used in experiments, it has been adopted as a HUAEC-stimulating factor. The $x$-elastin concentrations used in our experiments were chosen according to Faury et al. (1995) report. In an earlier study they demonstrated that $x$-elastin in the concentration range between $0.1 \mathrm{ng} / \mathrm{ml}$ and $1 \mu \mathrm{g} / \mathrm{ml}$ added to rat aortic ring ex vivo, precontracted with noradrenalin, induced an endothelium-dependent vasodilatation. This effect was attenuated by an eNOS inhibitor (L-NAME) and a cyclooxygenase inhibitor (indomethacin), thereby suggesting a number of mechanisms of EDP action. They also stimulated human umbilical vein endothelial cells (HUVEC) with $1 \mu \mathrm{g} / \mathrm{ml}$ of $x$-elastin. In this conditions, $x$-elastin induced 1.73-fold increase of intracellular $\mathrm{Ca}^{2+}$ (Faury et al., 1998). $x$-Elastin was used in our experiment at $0.5 \mu \mathrm{g} / \mathrm{ml}$ and $2.5 \mu \mathrm{g} / \mathrm{ml}$. These concentrations were chosen to elucidate the effects on eNOS expression at the mRNA and protein levels. Both in humans and experimental animals, EDP increased the elastolytic activity relating to the endothelium, smooth muscle cells and inflammation site infiltrating cells. An augmented elastolytic activity leads to an accelerated elastin degradation and eventually causes a release of huge amounts of EDP. This phenomenon is referred to as "a self-propelled vicious circle" of stimulations (Robert et al., 2010). Even $1 \mu \mathrm{g} / \mathrm{ml}$ of $x$-elastin accelerates neutrophil-induced LDL oxidation in vitro (Fulop et al., 2005). Moreover, it has been shown that $x$-elastin at $0.5 \mu \mathrm{g} / \mathrm{ml}$ and $2.5 \mu \mathrm{g} / \mathrm{ml}$ reflects both the EDP concentrations observed in people and concentrations leading to aorta dilatation ex vivo.

So far, there has been no research on the influence of elastin-derived peptides focusing simultaneously on eNOS gene expression and protein level. In our experiment, neither low $(0.5 \mu \mathrm{g} / \mathrm{ml})$ nor high $(2.5 \mu \mathrm{g} / \mathrm{ml})$ $x$-elastin concentrations influenced eNOS protein expression. Only the high $x$-elastin concentration resulted in a $31 \%$ increase of eNOS mRNA expression $(p \leq 0.01)$. Analyzing the influence of an elevated glucose concentration with and without the addition of $x$-elastin to the culture medium, we observed that $x$-elastin led to an increase in the quantity of eNOS protein. In the analogous experiment with LDL, a similar effect was obtained, although it did not reach the level of statistical significance. Elastin-derived peptides present proatherosclerotic properties and their pathogenic activity needs not to be related to the influence on eNOS gene expression. The blood concentration of EDP increases with age. Taking into consideration that the society is getting older, further research on the influence of EDP on the development of atherosclerotic process is crucial.

\section{Conflict of interest statement}

The authors state that there are no conflicts of interest.

\section{REFERENCES}

Braam B, Verhaar MC (2007) Understanding eNOS for pharmacological modulation of endothelial function: a translational view. Curr Pharm Des 13: 1727-1740.

Cai H, Harrison DG (2000) Endothelial dysfunction in cardiovascular diseases: the role of oxidant stress. Circ Res 87: 840-844.

Cosentino F, Hishikawa K, Katusic ZS, Luscher TF (1997) High glucose increases nitric oxide synthase expression and superoxide anion generation in human aortic endothelial cells. Circulation 96: 25-28.

Dötsch J, Hogen N, Nyúl Z, Hänze J, Knerr I, Kirschbaum M, Rascher W (2001) Increase of endothelial nitric oxide synthase and endothelin-1 mRNA expression in human placenta during gestation. Eur J Obstet Gynecol Reprod Biol 97: 163-167.

Faury G, Ristori MT, Verdetti J, Jacob MP, Robert L (1995) Effect of elastin peptides on vascular tone. J V asc Res 32: 112-119.

Faury G, Garnier S, Weiss AS, Wallach J, Fülöp T Jr, Jacob MP, Mecham RP, Robert L, Verdetti J (1998) Action of tropoelastin and synthetic elastin sequences on vascular tone and on free $\mathrm{Ca}^{2+}$ level in human vascular endothelial cells. Circ Res 82: 328-336.

Fulop T Jr, Wei SM, Robert L, Jacob MP (1990) Determination of elastin peptides in normal and arteriosclerotic human sera by ELISA. Clin Physiol Biochem 8: 273-282. 
Fulop T Jr, Larbi A, Fortun A, Robert L, Khalil A (2005) Elastin peptides induced oxidation of LDL by phagocytic cells. Pathol Biol (Paris) 53: 416-423.

Galle J, Wanner C (1998) Oxidized LDL and Lp(a). Preparation, modification, and analysis. Methods Mol Biol 108: 119-130.

Garland J (2002) Isolation of LDL (low density lipoprotein) from human plasma. www.protocol-online.org 2002; access: 15 May 2010 http://www.protocol-online.org/cgi-bin/prot/view_cache. cgi? ID $=2520$

Gmiński J, Dróżdż M (1991) Succinyl trialanine p-nitroanilide hydrolytic activities in plasma and the aorta of rabbits experimentally immunized with soluble elastin. Exp Pathol 43: 37-40.

Gmiński J, Dróżdż M, Ulfig-Maślanka R, Najda J (1991) Evaluation of elastin metabolism in children from families with high risk of atherosclerosis. Atherosclerosis 91: 185-189.

Hornebeck W, Robert L (1977) Elastase-like enzymes in aortas and human brest carcinomas: quantitative variations with age and pathology. Adv Exp Med Biol 79: 145-156.

Jiménez A, Arriero MM, López-Blaya A, González-Fernandez F, García R, Fortes J, Millás I, Velasco S, Sánchez De Miguel L, Rico L, Farré J, Casado S, López-Farré A (2001) Regulation of endothelial nitric oxide synthase expression in the vascular wall and in mononuclear cells from hypercholesterolemic rabbits. Circulation 104: 1822-1830.

Liao JK, Shin WS, Lee WY, Clark SL (1995) Oxidized low-density lipoprotein decreases the expression of endothelial nitric oxide synthase. J Biol Chem 270: 319-324.
Liaudet L, Vassalli G, Pacher P (2009) Role of peroxynitrite in the redox regulation of cell signal transduction pathways. Front Biosci 14: 4809-4814.

Ogut O, Brozovich FV (2008) The potential role of MLC phosphatase and MAPK signalling in the pathogenesis of vascular dysfunction in heart failure. J Cell Mol Med 12: 2158-2164.

Pritchard KA, Ackerman AW, Ou J, Curtis M, Smalley DM, Fontana JT, Stemerman MB, Sessa WC (2002) Native low-density lipoprotein induces endothelial nitric oxide synthase dysfunction: role of heat shock protein 90 and caveolin-1. Free Radic Biol Med 33: 52-62.

Robert L, Labat-Robert J, Robert AM (2010) Genetic, epigenetic and posttranslational mechanisms of aging. Biogerontology DOI: 10.1007/ s10522-010-9262-y.

Ross R (1999) Atherosclerosis — an inflammatory disease. N Engl J Med 340: 115-126.

Srinivasan S, Hatley ME, Bolick DT, Palmer LA, Edelstein D, Brownlee M, Hedrick CC (2004) Hyperglycaemia-induced superoxide production decreases eNOS expression via AP-1 activation in aortic endothelial cells. Diabetologia 47: 1727-1734.

Stone NJ, Bilek S, Rosenbaum S (2005) Recent National Cholesterol Education Program Adult Treatment Panel III update: adjustments and options. Am J Cardiol 96: 53E-59E. 